\title{
A história da disciplina acadêmica Didática Geral na Faculdade Nacional de Filosofia (FNFi) da Universidade do Brasil: um olhar arqueológico ${ }^{1}$
}

\section{The History of the Academic Discipline General Teaching at the National Faculty of Philosophy (FNFi) of the University of Brazil: a view from the archaeological studies}

\author{
Maria Verônica Rodrigues da Fonseca ${ }^{2}$
}

\begin{abstract}
RESUMO
$\mathrm{O}$ artigo apresenta resultados da pesquisa que investigou a história da disciplina acadêmica Didática Geral na Faculdade Nacional de Filosofia (FNFi) da Universidade do Brasil, no período compreendido desde 1939 até o ano de 1968, com o objetivo de compreender a prática discursiva que foi tecida e que tem significado para a referida disciplina como central na formação inicial de professores, em nível superior, no Brasil. O estudo foi desenvolvido a partir da articulação teórico-metodológica entre os estudos do campo do Currículo e, mais especificamente, em História do Currículo e das Disciplinas, desenvolvidos por Ivor Goodson e André Chervel, e os estudos arqueológicos de Michel Foucault, acerca da constituição histórica dos saberes, formulados a partir do conceito de discurso e de suas possibilidades de emergência e produção. A análise documental realizada aponta que três enunciados vão possibilitar a emergência de uma construção discursiva
\end{abstract}

DOI: $10.1590 / 0104-4060.39881$

1 Pesquisa financiada pela Coordenação de Aperfeiçoamento de Pessoal de Nível Superior - CAPES, com bolsa CAPES/Programa de Demanda Social (DS).

2 Escola Superior de Guerra - Divisão de Planejamento e Orientação Didático-Pedagógica - Fortaleza de São João. Rio de Janeiro, Rio de Janeiro, Brasil. Av. João Luiz Alves, s/nº - Urca. CEP: 22291-090. 
acerca da disciplina Didática como saber necessário ao professor - a centralidade da aprendizagem, a cientificidade da educação e a formação docente em nível universitário -, todos eles presentes no discurso pedagógico dos anos de 1920/30 buscavam responder às urgências postas pelo novo modelo de escolarização, em face da nova organização política e econômica brasileira dos anos de 1930. Trata-se de uma construção disciplinar específica, que se constitui na relação com o discurso psicológico da educação e, nessa interdiscursividade, objetivou ao ato de ensinar ser constituído como par da ação de aprender.

Palavras-chave: Currículo; História das Disciplinas; Didática Geral; formação de professores; Teoria do Discurso.

\begin{abstract}
The article brings the results from a study which focused on the history of the academic discipline General Didactics in the National Faculty of Philosophy (Faculdade Nacional de Filosofia - FNFi) at the University of Brazil in the period between 1939 and 1968. It aims to understand the discursive practice which was woven and let the referred discipline emerged and tuned into the core of teachers' initial preparation in Brazilian higher education, producing its own tradition as an integrated space of pedagogical studies. The research delves into the theoretical contributions of the field of Curriculum and more specifically, the studies in the History of Curriculum and History of Disciplines formulated by Ivor Goodson and Andre Chervel. To these references are added studies by Michel Foucault about the historical constitution of knowledge through a discourse concept and its emerging possibilities and production. Based on the document analysis, the study points that there are three statements that enable the need of discursive construction on Didactics as a discipline as essential knowledge to professors - the learning centrality, the scientific approach of education and of teacher training at the university level -,which were part of the pedagogical view in the 1920s and 30s and sought to answer the emergency posed by the new model of schooling in the face of Brazil's new political and economic organization in the 1930s. This is a particular discursive formation that is constituted in relation to the psychological discourse of education - which focused on learning - and in this interdiscursive process, it aimed teaching as forming a pair with the action of learning.
\end{abstract}

Keywords: Curriculum; History of the Disciplines; General Didactics; teacher preparation; Discourse Theory. 


\section{Introdução}

O presente artigo apresenta resultados da pesquisa que investigou a história da disciplina acadêmica Didática Geral na Faculdade Nacional de Filosofia (FNFi), da Universidade do Brasil, no período compreendido entre 1939 - ano da criação da Secção Especial de Didática, na referida instituição, que tinha a finalidade expressa de "preparar candidatos para o magistério secundário e normal" , conforme o processo de formação de professores idealizado por Gustavo Capanema, no Governo de Getúlio Vargas, - até 1968, quando a FNFi é extinta e em seu lugar é organizada a Faculdade de Educação da Universidade Federal do Rio de Janeiro(FE/UFRJ).

O estudo foi desenvolvido a partir da articulação teórico-metodológica entre os estudos do campo do Currículo e, mais especificamente, em História do Currículo e das Disciplinas, desenvolvidos por Ivor Goodson, e os estudos arqueológicos de Michel Foucault, acerca da constituição histórica dos saberes, formulados a partir do conceito de discurso e de suas possibilidades de emergência e produção.

A investigação valeu-se do confronto e análise de fontes documentais, do chamado currículo escrito: ementas, programas, resoluções, pareceres, e outros documentos de cunho geral, elaborados na própria instituição investigada, bem como leis, relatórios, estatutos, manifestos de grupos acadêmicos, livros editados com a finalidade didática e outros materiais didáticos diversos guardados e disponíveis para consulta nos arquivos do Centro de Pesquisa e Documentação de História Contemporânea do Brasil da Fundação Getúlio Vargas (CPDOC/ FGV) e do Programa de Estudos e Documentação Educação e Sociedade da Universidade Federal do Rio de Janeiro (PROEDES/UFRJ). Especialmente neste artigo, são apresentados resultados obtidos a partir da análise das seguintes fontes documentais: O Manifesto dos Pioneiros da Educação Nova, publicado em 1932, e o livro didático Sumário de Didática Geral, de Luiz Alves de Mattos. Buscou-se, nestas fontes, identificar as condições de existência de determinados discursos que se tornaram reais e foram efetivamente pronunciados. Porque nesses documentos "está materializado, presente e vivo o discurso de uma época." (FISCHER, 2012, p. 44).

3 BRASIL. Ministério da Educação e Saúde. Decreto-Lei n ${ }^{\circ} 1.190$, de 04 de abril de 1939. Organiza a Faculdade Nacional de Filosofia. Capítulo I, Art. 1º, Alínea c. Disponível em: <http:// www2.camara.leg.br/legin/fed/declei/1930-1939/decreto-lei-1190-4-abril-1939-349241-publicacaooriginal-1-pe.html>. Acesso em: 10 fev. 2015. 
Ao focalizar a história da disciplina acadêmica Didática Geral, o estudo teve por objetivo compreender a prática discursiva tecida e que tem objetivado a referida disciplina como central na formação inicial de professores, em nível superior, no Brasil. Tornando-a estável em distintos currículos de formação de professores, fazendo com que, mesmo nos momentos de grandes reformulações, ela tenha sido reconstituída, reinventada e reafirmada. (GOODSON, 1997, p. 20). Trata-se de uma disciplina que permanece presente tanto na formação dos professores da Educação Infantil e dos anos iniciais do Ensino Fundamental, quanto nos Cursos de Licenciaturas que habilitam professores das diferentes disciplinas para os anos finais do Ensino Fundamental e para o Ensino Médio até os dias atuais.

\section{Caminhos trilhados para a construção sócio-histórica da disciplina acadêmica Didática Geral na Faculdade Nacional de Filosofia (FNFi)}

O estudo se afirma inserido no marco teórico-metodológico da História do Currículo que, construído na perspectiva da Nova Sociologia da Educação (NSE), tem se voltado para explicar as transformações ocorridas em determinadas disciplinas ao longo do tempo e identificar fatores mais diretamente ligados às mudanças de conteúdos. Investigando instituições de ensino e o modo como nelas é selecionado e organizado o conhecimento, bem como as ideias que fundamentam tal seleção e organização, por entender que "a educação é sempre um conjunto de escolhas culturais, algumas conscientes e outras inconscientes. Segue-se daí que o currículo é sempre uma seleção e uma organização do saber disponível em uma determinada época". (YOUNG, 2000, p. 28).

No Brasil, ao final dos anos de 1980 e início dos anos de 1990, com o processo de redemocratização do país, a implementação de inúmeras reformas curriculares levou à intensificação de pesquisas que se dedicam à compreensão do processo de construção sócio-histórica de diferentes currículos e disciplinas, buscando o entendimento dos "determinantes sociais e políticos do conhecimento educacionalmente organizado". (SILVA, 2005, p. 10). Tais investigações se voltaram para tentar descobrir quais conhecimentos foram considerados válidos de serem ensinados em certa época e determinar de que forma essa validade foi sendo estabelecida, com vistas a entender como tem se constituído seu processo de estabilidade e de mudança, em uma perspectiva que buscava ultrapassar as "análises limitadas às ações do Estado como principal, e por vezes agente exclusivo dos processos de mudanças educacionais". (BITTENCOURT, 2003, p. 13). 
Nesse sentido, as investigações têm sido desenvolvidas na articulação de estudos formulados por historiadores do currículo de língua inglesa, cuja maior influência é a produção de Ivor Goodson, e do teórico francês associado à História da Educação André Chervel. Esses autores têm buscado, em seus estudos, explicar as transformações ocorridas em determinadas disciplinas ao longo do tempo e identificar fatores mais diretamente ligados às mudanças de conteúdos de ensino.

Esse movimento de articulação entre os campos do Currículo e da História da Educação é apontado em trabalho realizado por Vilela et al. (2011, p. 1), que identificou "uma aproximação entre tais estudos para além de seus recortes temáticos temporais, tanto no que se refere aos referenciais teórico-metodológicos quanto no estabelecimento de diálogos com outras áreas de conhecimento".

Conforme ressaltado por Goodson (2001), uma vantagem do diálogo estabelecido entre a História do Currículo e a História da Educação, para a construção da história das disciplinas, é o fato de que ambas têm se beneficiado dos conhecimentos inovadores produzidos no âmbito da História Cultural e da História Social do Conhecimento que, "graças aos esclarecimentos de investigadores como Michel Foucault tem feito progresso no sentido da compreensão da relação entre a construção histórica do conhecimento pelos profissionais e a disciplina". (GOODSON, 2001, p. 100). Tendo em vista que, para Foucault (2009), os estudos arqueológicos do discurso possibilitam interrogar como se tornou possível que um saber, em determinado momento histórico, ascendesse como um saber disciplinarizado.

Essa possibilidade de articulação teórico-metodológica se fortalece na própria percepção de Foucault (2012) sobre a disciplina ao diferenciá-la da ciência, pelo princípio de limitação, e entendendo-a em um processo de construção ao afirmar que:

[...] para que haja disciplina, é preciso, por conseguinte, que haja a possibilidade de formular, e de formular indefinidamente, novas proposições. Mas há mais; e há mais, sem dúvida, para que haja menos: uma disciplina não é a soma de tudo aquilo que pode ser dito de verdadeiro a propósito de qualquer coisa; nem mesmo é o conjunto de tudo aquilo que, a propósito de um mesmo dado, pode, pelo princípio de coerência ou sistematização, ser aceite [...] são feitas tanto de erros como de verdades, erros que não são resíduos ou corpos estranhos, mas que tem funções positivas, uma eficácia histórica, um papel muitas vezes indissociável daquele das verdades. (FOUCAULT, 2012, p. 29-30). 
Destaca-se, ainda, a potencialidade da análise arqueológica foucaultiana do discurso, para o estudo sócio-histórico das disciplinas, porque os estudos arqueológicos possibilitam uma visão que amplia a perspectiva que entende os fatos em uma relação de causa e efeito, permitindo que sejam interpretados como constituídos em uma teia de relações em que um fato influencia e constitui o outro, como se tornam possíveis determinadas "descobertas [grifo do autor] e como puderam ser seguidas de outras que as retomaram, corrigiram e eventualmente anularam". (FOUCAULT, 2009, p. 48).

Ressalta-se, que ao optar por construir o desenho da pesquisa articulando esses referenciais - quais sejam, os estudos sócio-históricos do currículo e das disciplinas aos estudos arqueológicos do discurso de Michel Foucault -, o trabalho fundamentou-se, ainda, nas indicações de importantes teóricos dos referidos campos quanto à viabilidade de que tais estudos sejam articulados. Moreira (2004), por exemplo, considera que, no campo do Currículo:

As reflexões sobre saber, poder, subjetividade, ética, linguagem, discurso, tão caras ao filósofo, são indispensáveis para os que se dedicam ao ofício de pensar e fazer currículos e que reconhecem o quanto as complexas práticas e relações implicadas nessas tarefas ainda precisam ser problematizadas e compreendidas. (MOREIRA, 2004, p. 614).

No que se refere à História da Educação, Gondra (2011, p. 297) chama a atenção para o fato de que Foucault tem sido usado, nessa área, como "uma caixa de ferramentas", destacando as "contribuições que ajudaram a redefinir contornos e limites dos canteiros da história, mas também os da própria oficina e ofício do historiador", ressaltando a riqueza de seu método arqueológico que acena:

Para a capacidade de se refletir acerca das ciências do homem enquanto saberes, investigando as condições de sua existência com base na análise do que dizem, como dizem e por que dizem, exigindo para tanto, a realização de uma análise conceitual capaz de estabelecer descontinuidades no nível dos saberes. (GONDRA, 2011, p. 296).

Foi a partir dessas perspectivas que esta pesquisa incorporou, aos marcos teóricos da História do Currículo e da História da Educação, influências dos estudos arqueológicos do discurso, formulados por Michel Foucault, com o 
objetivo de compreender como a disciplina Didática Geral tornou-se o que se diz dela hoje, analisando sua possibilidade de emergência, continuidades e transformações discursivas que têm marcado o seu percurso sócio-histórico.

\section{Possibilidades dos Estudos Arqueológicos Foucaultianos para o estudo sócio-histórico das disciplinas}

Conforme aponta Veiga-Neto (2007), considerando o critério metodológico, a obra de Michel Foucault é tradicionalmente definida como possuindo três fases: a arqueológica, a genealógica e a ética. $\mathrm{O}$ estudo desenvolveu-se a partir das indicações foucaultianas acerca dos processos que possibilitam o surgimento de um discurso e que foram abordados em A Ordem do Discurso, significativa obra da chamada fase genealógica, assim como de suas reflexões acerca do método arqueológico apresentado no livro A Arqueologia do Saber. Este segundo trabalho, de acordo com Machado (2007, p. 143), trata-se de um empreendimento que pretende esclarecer dúvidas metodológicas acerca do processo pelo qual se busca descrever e compreender as regras que possibilitam a constituição discursiva de um determinado saber. Ou seja, a obra apresenta um caminho metodológico que busca compreender como determinado discurso é constituído, mostrando, "porque não poderia ser outro, como exclui qualquer outro, como ocupa, no meio dos outros e relacionado a eles, um lugar que nenhum outro poderia ocupar". (FOUCAULT, 2009, p. 31).

Segundo Foucault (2009), a história arqueológica volta-se para tentar revelar as práticas discursivas, na medida em que dão lugar a um saber e, em especial, quando se refere a um saber que assume o status de científico, buscando "definir como, segundo que regularidade e graças a que modificações ela pode dar lugar aos processos de epistemologização, atingir as normas da cientificidade e, talvez, chegar ao limiar da formalização". (FOUCAULT, 2009, p. 213). Tal história busca delinear o feixe de relações que se estabeleceram e levaram à formação de "uma prática discursiva que se desenrola entre outras práticas e se articula com ela". (FOUCAULT, 2009, p. 218). Afinal, o discurso é essencialmente histórico e necessita ser analisado no tempo em que se desenvolveu.

Outra possibilidade de análise refere-se à derivação enunciativa, tendo em vista que os discursos não podem ser entendidos como simples criações, inspirações, ou como originados em enunciado inicial, pois os enunciados são sempre relacionados. Isto é, todo enunciado se relaciona a outros que o antecedem e se relacionam entre si. 
$\mathrm{Na}$ análise arqueológica devem ser consideradas, ainda, as relações entre as formações discursivas e formações não discursivas, ou seja, as possibilidades de articulação entre os discursos e os acontecimentos econômicos, políticos e as instituições, cuidando, entretanto, para não se estabelecer "continuidades culturais ou isolar mecanismos de causalidade". (FOUCAULT, 2009, p. 183). Nesta perspectiva de se estabelecer campos de relações, o que se propõe é mostrar como uma prática não discursiva, um acontecimento político, por exemplo, faz parte das condições de emergência, de inserção e de funcionamento de um determinado discurso. Afinal, o que a análise arqueológica "quer revelar é o nível singular em que a história pode dar lugar a tipos definidos de discurso que têm, eles próprios, seu tipo de historicidade e que estão relacionados com todo um conjunto de historicidades diversas". (FOUCAULT, 2009, p. 186). Como aponta Araújo (2008, p. 64), a história arqueológica possibilita "analisar aquilo que uma época pode constituir como objeto para um saber no nível discursivo", sem se preocupar, no entanto, com quem formulou tal saber, mas focando em como foi possível que este saber tenha sido produzido.

Com base nesses aspectos, o estudo investiu na análise arqueológica para pensar as regularidades presentes nos discursos que significaram a disciplina Didática Geral na formação de professores na FNFi, a partir da compreensão de articulações específicas presentes nos discursos que têm constituído o seu ensino. Buscando compreender uma prática discursiva que tem gerado análises no tempo presente, por exemplo, de que, "a despeito da intensa produção do movimento crítico da didática desde o início dos anos 1980, mantém-se a concepção de didática prescritiva, instrumental”. (LIBÂNEO, 2010, p. 81). Ou, ainda, que a persistência de uma "concepção técnico-instrumental e o ensino focalizado na teoria em detrimento da prática, [tem fortalecido] a descontextualização dos conteúdos da Didática". (VEIGA, 2010, p. 47). Afinal, uma das tarefas da arqueologia é apresentar "como se formaram uma prática discursiva e um saber revolucionário que estão envolvidos em comportamentos e estratégias, que dão lugar a uma teoria da sociedade e que operam a interferência e a mútua transformação de uns e outros". (FOUCAULT, 2009, p. 218).

Na seção seguinte, são apresentados então alguns resultados do estudo concluído, a partir desta articulação teórica.

\section{Emergência e construção discursiva da disciplina acadêmica Didática Geral, na FNFi, da Universidade do Brasil}

Os anos de 1930 constituem-se, na história brasileira, como um momento em que se iniciou a organização de um sistema de educação que viesse atender 
às novas necessidades postas a uma nação que, em meio à crise do modelo agrário exportador, iniciada em 1929, começava seu processo de industrialização e não possuía uma população com mão de obra qualificada para atuar nesse novo cenário econômico. Tal realidade exigia mudanças no processo educativo até então existente no país, cabendo ao Estado brasileiro construir uma política que gerasse a necessária renovação à educação nacional. É neste contexto que é criado o Ministério dos Negócios da Educação e Saúde Pública (MES), pelo Decreto $n^{\circ} 19.492$, de 14 de novembro de 1930. A criação do MES "significou o início de um processo no qual o Estado definiu sua competência no campo específico da educação, colocando sob seu poder um indispensável meio de controle e persuasão". (MORAES, 1992, p. 293).

Em meio a esse cenário de renovação, é publicado em 1932 O Manifesto dos Pioneiros da Educação Nova. Conforme caracteriza Xavier (2002, p. 3), "os Manifestos são sempre a formalização de um rito de transição, sua intenção é fazer uma declaração pública de doutrinas ou propósitos de interesse geral, marcar uma mudança, inaugurar um novo momento". Neste sentido, pode-se afirmar que o Manifesto se configurou como um esforço conjunto pela organização do sistema educacional brasileiro, em que se pretendia romper com o modelo de ensino tradicional presente na educação no Brasil até então, conforme expresso a seguir:

\begin{abstract}
Nessa nova concepção da escola, que é uma reação contra as tendências exclusivamente passivas, intelectualistas e verbalistas da escola tradicional, a atividade que está na base de todos os seus trabalhos, é a atividade espontânea, alegre e fecunda, dirigida à satisfação das necessidades do próprio indivíduo. Na verdadeira educação funcional deve estar, pois, sempre presente, como elemento essencial e inerente à sua própria natureza, $\mathrm{o}$ problema não só da correspondência entre os graus do ensino e as etapas da evolução intelectual fixadas sobre a base dos interesses, como também da adaptação da atividade educativa às necessidades psicobiológicas do momento. (O MANIFESTO dos Pioneiros, 1932, p. 196).
\end{abstract}

Trabalhando a partir de uma perspectiva histórica que busca analisar os documentos não como expressão de uma verdade que reconstrói o que os homens fizeram ou disseram, mas, sim, analisa o documento em seu interior, elaborando-o, procuro seguir pistas que me permitam "definir no próprio tecido documental, unidades, conjuntos, séries, relações”. (FOUCAULT, 2009, p. 7). Interessou especificamente no texto do Manifesto de 1932 inventariar o 
entrelaçamento entre o discurso que se constituía sobre a disciplina Didática na relação com um discurso educacional renovador que vai levar ao aparecimento "do enunciado do indivíduo como portador de capacidades humanas a serem desdobradas e constituídas pelo ato educativo”. (CARLOS, 2005, p. 240).

Conforme afirma Nogueira-Ramirez (2009), no final do século XIX, a concepção de educação que enfatizava a formação do caráter e a instrução é transformada com o surgimento do conceito de aprendizagem, a partir de certa "moral biológica" [grifo do autor], fundamentada em uma série de conceitos sobre o crescimento, desenvolvimento e adaptação do indivíduo (organismo) ao seu meio. (NOGUEIRA-RAMIREZ, 2009, p. 242).

No Brasil, a influência do discurso biológico e psicológico no campo da Educação é facilmente percebida no principal documento que formalizou as intenções de renovação que se pretendia que fossem efetivadas na educação brasileira - O Manifesto dos Pioneiros da Educação Nova -, onde se lê, por exemplo:

[...] Desprendendo-se dos interesses de classes, a que ela tem servido, a educação perde o "sentido aristológico", para usar a expressão de Ernesto Nelson, deixa de constituir um privilégio determinado pela condição econômica e social do indivíduo, para assumir um "caráter biológico", com que ela se organiza para a coletividade em geral, reconhecendo a todo o indivíduo o direito a ser educado até onde o permitam as suas aptidões naturais, independente de razões de ordem econômica e social. [...] Ela tem, por objeto, organizar e desenvolver os meios de ação durável com o fim de "dirigir o desenvolvimento natural e integral do ser humano em cada uma das etapas de seu crescimento", de acordo com uma certa concepção do mundo. (O MANIFESTO dos Pioneiros, 1932, p. 191).

Segundo apontado por Vidal (2010), embora, já ao final do século XIX, a centralidade da criança nas relações de aprendizagem, a exaltação do ato de observar e de intuir na construção do conhecimento já fossem enunciados em relatórios de inspetores, por exemplo, nos anos de 1920, "a ruptura entre uma e outra formação discursiva não vinha associada a uma alteração dos enunciados, mas de seus significados". (VIDAL, 2010, p. 497-498). Afinal, é difícil falar subitamente de uma coisa nova, que jamais tenha sido dita. (FOUCAULT, 2009). E, assim, "uma nova dinâmica impulsionava as relações escolares. O aluno assumia soberanamente o centro dos processos de aquisição do conhecimento escolar: aprendizagem em lugar do ensino". (VIDAL, 2010, p. 498). 
A partir do conceito de "duplo" formulado em estudo realizado por Popkewitz (2001), sobre a construção de relações entre diferentes discursos, que se estabelecem como um "par binário" e que vão se constituindo na diferença e na oposição de um ao outro na relação discursiva, o estudo aponta que a centralidade da aprendizagem do aluno assumida no discurso educacional renovador escolanovista ${ }^{4}$ dos anos de 1930 produziu a possibilidade de construção do ensino a ser conduzido pelo professor como o "outro" dessa relação, que vai 'disputar um lugar' nessa prática discursiva que se entrecruza no discurso pedagógico. Ou seja, o discurso educacional existente até então que significava o enunciado da instrução como tarefa educativa, como central no discurso pedagógico, vai ser ressignificado a partir da enunciação da aprendizagem que irá constituir a nova ordem do discurso.

Tem-se, então, o que Foucault denomina de contradições intrínsecas, consideradas pertinentes na análise arqueológica, que, "nascidas em um ponto do sistema de formações, fazem surgir subsistemas. Estas contradições são compatíveis, são duas maneiras de formar enunciados, caracterizados por certos conceitos e certas escolhas estratégicas" (FOUCAULT, 2009, p. 173) que vão estabelecer relações entre si. No texto a seguir, evidencia-se esse processo:

Para bem ensinarmos precisamos, como professores, ter preliminarmente uma noção clara e exata do que seja realmente 'aprender' e 'ensinar', [grifos do autor] pois que existe uma relação direta e necessária, não apenas teórica, mas também prática. Entre esses dois conceitos básicos da Didática. (MATTOS, 1964, p. 65).

O estudo defende, então, que é a interação desses dois conceitos - aprender e ensinar - que vão dar singularidade ao discurso da Didática Geral no momento histórico investigado. Assim, o discurso da didática no Brasil dos anos de 1930 se constituiu nessa contradição intrínseca entre ensino e aprendizagem. Isto é, o discurso da disciplina acadêmica Didática Geral teve a possibilidade

4 Discurso educacional surgido ao final do século XIX e que se fortalece após o fim da Primeira Guerra Mundial, fundamentado nos estudos formulados pela Psicologia sobre a natureza de aprendizagem da criança, foca a atividade interessada e espontânea como fonte do conhecimento para favorecer a melhor execução das atividades humanas e a importância da participação do indivíduo na construção de uma sociedade democrática. No Brasil, a "Escola Nova produziu enunciados que, desenhando alterações no modelo escolar, desqualificam aspectos da forma e a cultura em voga nas escolas, aglutinadas em torno do termo tradicional. Era pela diferença quanto às práticas e saberes escolares anteriores que se construía a representação do novo." (VIDAL, 2010, p. 497). 
de emergir, se fez possível, no momento histórico em que o foco desvia da instrução e da inerente centralidade na figura do docente, do "protagonismo professoral" (CASTANHO; CASTANHO, 2008) característico da denominada educação tradicional, em que a escola se constituía em "um aparelho formal e rígido, sem diferenciação regional, inteiramente desintegrado em relação ao meio social" (O MANIFESTO dos Pioneiros, 1932, p. 196), para focar no indivíduo, aquele que aprende: o aluno. Assim, a partir do enunciado sobre aprendizagem do aluno, constrói-se discursivamente o entendimento de que cabe ao professor a responsabilidade pelo desenvolvimento do indivíduo que aprende. Embora o docente não seja mais o protagonista do processo de instrução, "o magistério é uma profissão de altas e complexas responsabilidades para com o indivíduo e para com a sociedade [...] visto ser o professor o principal responsável pela formação da inteligência e personalidade de seus alunos". (MATTOS, 1964, p. 27).

No entanto, como explicitado no texto do Manifesto,

[...] no magistério, o espírito novo, o gosto da crítica e do debate e a consciência da necessidade de um aperfeiçoamento constante, ainda não se podia considerar inteiramente aberto o caminho às grandes reformas educacionais. [...] A maioria dos espíritos, tanto da velha como da nova geração ainda se arrastam, porém, sem convicções, através de um labirinto de idéias vagas. (O MANIFESTO dos Pioneiros, 1932, p. 190).

Ressalta-se, então, que, face à importância da educação para o projeto de sociabilidade republicana e, mais especialmente o processo de escolarização, o Manifesto põe em circulação, também, a ideia de que os professores necessitam de profissionalização. Afinal, a maior parte dos professores era:

[...] recrutada em todas as carreiras, sem qualquer preparação profissional, como os professores do ensino secundário e os do ensino superior (engenharia, medicina, direito, etc.), entre os profissionais dessas carreiras, que receberam, uns e outros, do secundário a sua educação geral. O magistério primário, preparado em escolas especiais (escolas normais), de caráter mais propedêutico, e, às vezes misto, com seus cursos geral e de especialização profissional, não recebe, por via de regra, nesses estabelecimentos, de nível secundário, nem uma sólida preparação pedagógica, nem a educação geral em que ela deve basear-se. A preparação dos professores, como se vê, é tratada entre nós, de maneira diferente, quando não é inteiramente descuidada, como se a função educacional, 
de todas as funções públicas a mais importante, fosse a única para cujo exercício não houvesse necessidade de qualquer preparação profissional. (O MANIFESTO dos Pioneiros, 1932, p. 200).

O discurso acerca da disciplina Didática emerge, então, em um momento no qual se critica a inexistência de formação docente para atuação no ensino secundário. Afinal, o ensino se fundamentava apenas no saber a ser ensinado - o conteúdo -, e se constrói, então, o enunciado do saber ensinar. Enfatiza-se, discursivamente, a defesa de que esta formação profissional para a docência tem como locus a universidade. Observe:

Todos os professores, de todos os graus, [...] devem, no entanto, formar o seu espírito pedagógico, conjuntamente, nos cursos universitários, em faculdades ou escolas normais, elevadas ao nível superior e incorporadas às universidades. [...] A formação universitária dos professores não é somente uma necessidade da função educativa, mas o único meio de, elevando-lhes em verticalidade a cultura, e abrindo-lhes a vida sobre todos os horizontes, estabelecer, entre todos, para a realização da obra educacional, uma compreensão recíproca, uma vida sentimental comum e um vigoroso espírito comum nas aspirações e nos ideais. [...] Os professores de ensino primário e secundário, assim formados, em escolas ou cursos universitários, sobre a base de uma educação geral comum, dada em estabelecimentos de educação secundária, não fariam senão um só corpo com os do ensino superior, preparando a fusão sincera e cordial de todas as forças vivas do magistério. (O MANIFESTO dos Pioneiros, 1932, p. 200-201).

Associando-se, ainda, ao enunciado da formação docente em nível universitário, tem-se a racionalidade científica que passa a vigorar no discurso pedagógico brasileiro, aspecto que pode ser evidenciado no seguinte trecho do texto do Manifesto:

Esse empirismo grosseiro, que tem presidido ao estudo dos problemas pedagógicos, postos e discutidos numa atmosfera de horizontes estreitos, tem as suas origens na ausência total de uma cultura universitária e na formação meramente literária de nossa cultura. [...] um educador pode bem ser um filósofo e deve ter a sua filosofia de educação; mas, trabalhando 
cientificamente nesse terreno, ele deve estar tão interessado na determinação dos fins de educação, quanto também dos meios de realizá-los. [...] se tem um espírito científico, empregará os métodos comuns a todo gênero de investigação científica, podendo recorrer a técnicas mais ou menos elaboradas e dominar a situação, realizando experiências e medindo os resultados de toda e qualquer modificação nos processos e nas técnicas, que se desenvolveram sob o impulso dos trabalhos científicos na administração dos serviços escolares. [...] Os trabalhos científicos no ramo da educação já nos faziam sentir, em toda a sua força reconstrutora, o axioma de que se pode ser tão científico no estudo e na resolução dos problemas educativos, como nos da engenharia e das finanças. (O MANIFESTO dos Pioneiros, 1932, p. 188-189).

São, portanto, esses três enunciados - a centralidade da aprendizagem, a cientificidade da educação e a formação docente em nível universitário -, presentes no discurso pedagógico dos anos de 1920/30, que vão possibilitar a emergência de uma construção discursiva acerca da disciplina Didática como saber necessário ao professor. Afinal, embora esses enunciados já estivessem presentes e fossem ditos antes, não chegavam a constituir, de "modo algum uma disciplina autônoma". (FOUCAULT, 2009, p. 201). Ou seja, a disciplina acadêmica Didática Geral se constitui discursivamente como um "imperativo ético para todo aquele que pretende se dedicar ao magistério e à educação da juventude." (MATTOS, 1964, p. 27). Afinal, o professor deixa de ser o centro da instrução, e necessita de formação especializada e cientificamente orientada para possibilitar a aprendizagem, cabendo à Didática Geral assumir esse papel.

A análise documental aponta, ainda, que embora nas décadas de 1920 e 1930 se evidencie a preocupação com a organização de um processo de formação específica e especializada para o exercício do magistério, ainda não existia a constituição de um "discurso da didática", ou o uso deste termo para designar um saber, uma área específica de conhecimento ou disciplina. Isto é, a ideia de uma disciplina assim denominada não se fez presente nos diferentes ordenamentos legais que organizavam a formação de docentes para o sistema educacional brasileiro que pela primeira vez se constituía.

Somente a partir de 1939, com a criação da FNFi da Universidade do Brasil, cujo modelo de formação serviu de padrão para todo o país, é que se pode afirmar que foi generalizado o paradigma de formação de professores em nível superior associado diretamente à criação de um Curso de Didática e de uma disciplina acadêmica específica denominada Didática Geral. Isto é, ainda não havia um sistema de ideias construído que atribuísse à Didática Geral determinados pressupostos teóricos e metodológicos característicos de uma disciplina. 
O estudo defende, assim, que essa construção discursiva tem sua possibilidade de emergência "sob condições positivas de um feixe de relações [...] estabelecidas entre instituições, processos econômicos e sociais" (FOUCAULT, 2009, p. 50), em que se destaca a criação de uma instituição específica: a FNFi da Universidade do Brasil. Destaca, assim, que se tem aqui "o momento a partir do qual uma prática discursiva se individualiza e assume sua autonomia". (FOUCAULT, 2009, p. 208).

Trata-se de uma prática discursiva que será reforçada, apoiando-se em outras práticas que se estabelecem e justificam a necessidade desta formação, como, por exemplo, a constituição de um sistema de ensino nacional, por uma política educacional que requer legalmente formação especializada para o exercício da docência, nas instituições escolares. Um discurso que irá construir um sentido para o denominado processo ensino-aprendizagem, em uma interdiscursividade que pode ser percebida, por exemplo, no perfil estabelecido para orientar a seleção do professor que assumiria a cadeira de Didática Geral e Especial da FNFi, considerando o "eixo da formação real do professor secundário". Para o seu provimento, foi especificado que:

[...] o professor deverá, antes de tudo, conhecer muito bem os problemas do ensino secundário; estar a par das modernas teorias de aprendizagem, conhecer suficientemente biologia educacional e psicologia educacional; ter conhecimento de educação comparada, no ramo; ter a visão necessária e tacto para harmonizar o trabalho de seus assistentes que deverão ser numerosos; um para cada licença. (PROFESSORES das Cadeiras Pedagógicas da FNFi, [193?]) 5 .

\section{Considerações finais}

O processo de investigação aqui apresentado buscou construir uma possibilidade teórico-metodológica que ampliasse o modelo de investigação que vem sendo realizado para compreender os processos de construção sócio-histórica de currículos e disciplinas acadêmicas e escolares, incluindo as clássicas teorizações desenvolvidas nos campos do Currículo e da História da Educação e a teorização arqueológica do discurso formulada por Michel Foucault.

5 Conforme registro em manuscrito "Professores das cadeiras pedagógicas da FNFi", [193?], constante do acervo Gustavo Capanema - CPDOC/FGV. 
A partir dessa articulação teórica foi possível identificar que em meio a interdiscursividade e a práticas não discursivas se estabeleceu um jogo de relações que tornou possível ao saber da Didática Geral galgar ao status de ser reconhecido como verdadeiro, a partir da criação do Curso e da Seção de Didática no âmbito da Faculdade Nacional de Filosofia (FNFi) da Universidade do Brasil, conforme estabelecido no Decreto-Lei n ${ }^{\circ} 1.190$, de 04 de abril de 1939.

A disciplina acadêmica Didática Geral emerge e se entrecruza com os discursos psicológico e biológico, que focam a figura do indivíduo que aprende, e o discurso pedagógico, que centraliza a importância da formação docente. Ou seja, é a interação de dois conceitos - aprender e ensinar - que vão dar singularidade ao discurso da disciplina acadêmica Didática Geral no momento histórico investigado.

\section{REFERÊNCIAS}

ARAÚJO, Inês Lacerda. Foucault e a crítica do sujeito. Curitiba: Ed. UFPR, 2008.

BITTENCOURT, Circe Maria Fernandes. Disciplinas escolares: história e pesquisa. In: OLIVEIRA, M. A.; RANZI, S. M. F. (Orgs.). História das disciplinas escolares no Brasil: contribuições para o debate. Bragança Paulista: EDUSF, 2003. p. 09-38.

CARLOS, Erenildo João. A Formação do discurso sobre a educação de adultos: de 1889 à década de 1940. Tese (Doutorado) - Universidade Federal do Ceará, Ceará, 2005. Disponível em: $<$ http://paedagogiumejc.blogspot.com.br/p/escritos.html $>$. Acesso em: 10 jan. 2014.

CASTANHO, Maria Eugênia L. M; CASTANHO, Sérgio Eduardo Montes. Contribuição ao estudo da história da didática no Brasil. In: REUNIÃO ANUAL DA ANPED, 31., 2008, Caxambu. Anais... Caxambu, 2008. Disponível em: <http://www.anped.org.br/ reunioes/31 ra/1 trabalho/GT04-4031--Int.pdf>. Acesso em: 07 ago. 2012.

FISCHER, Rosa Maria B. Trabalhar com Foucault: arqueologia de uma paixão. Belo Horizonte: Autêntica, 2012.

FOUCAULT, Michel. Arqueologia do Saber. Rio de Janeiro: Forense Universitária, 2009.

FOUCAULT, Michel. A ordem do discurso - aula inaugural no Collège de France. São Paulo: Edições Loyola, 2012.

GONDRA, José Gonçalves. Paul-Michel Foucault - uma caixa de ferramentas para a história da educação? In: FARIA FILHO, Luciano M. (Org.). Pensadores Sociais e História da Educação. Belo Horizonte: Autêntica, 2011. p. 293-311. 
GOODSON, Ivor F. A construção social do currículo. Lisboa: Educa, 1997.

GOODSON, Ivor F. O currículo em mudança - estudos na construção social do currículo. Porto: Porto Editora, 2001.

LIBÂNEO, José Carlos. A integração entre didática e epistemologia das disciplinas: uma via para a renovação dos conteúdos da didática. Belo Horizonte: Autêntica, 2010.

MACHADO, Roberto. Foucault, a ciência e o saber. Rio de Janeiro: Zahar, 2007.

MATTOS, Luiz Alves. Sumário de Didática Geral. Rio de Janeiro: Aurora, 1964.

MORAES, Maria Célia Marcondes. Educação e Política nos Anos 30: a Presença de Francisco Campos. Revista Brasileira de Estudos Pedagógicos, Brasília, v. 73, n. 174, p. 291-321, maio/ago. 1992.

MOREIRA, Antonio Flavio Barbosa. O pensamento de Foucault e suas contribuições para a educação. Educação e Sociedade, Campinas, v. 25, n. 87, p. 611-615, maio/ago. 2004. Disponível em: <http://www.cedes.unicamp.br>. Acesso em: 21 jun. 2012.

NOGUEIRA-RAMIREZ, Carlos Ernesto. Governamento Pedagógico: da sociedade do ensino para a sociedade da aprendizagem. Tese (Doutorado) - Universidade Federal do Rio Grande do Sul, Porto Alegre, 2009.

O MANIFESTO dos Pioneiros da Educação Nova (1932). Revista HISTEDBR On-line, Campinas, n. especial, p. 188-204, ago. 2006. Disponível em: $<$ http://www.histedbr.fae. unicamp.br/revista/edicoes/22e/doc1_22e.pdf>. Acesso em: 14 mar. 2014.

POPKEWITZ, Thomas S. Lutando em defesa da alma. Porto Alegre: Artmed Editora, 2001.

PROFESSORES das Cadeiras Pedagógicas da FNFi. [1939]. Acervo Gustavo Capanema do CPDOC/FGV.

SILVA, Tomaz Tadeu. Apresentação. In: GOODSON, I. F. Currículo: teoria e história. Petrópolis: Vozes, 2005. p. 7-13.

VEIGA, Ilma Passos A. Por dentro da didática: um retrato de três Pesquisas. In: ENCONTRO NACIONAL DE DIDÁTICA E PRÁTICA DE ENSINO - Convergências e Tensões no campo da formação e do trabalho docente, XV., 2010, Belo Horizonte. Anais... Belo Horizonte: Autêntica, 2010, p. 47-59.

VEIGA-NETO, Alfredo. Foucault e a Educação. Belo Horizonte: Autêntica, 2007.

VIDAL, Diana Gonçalves. Escola Nova e Processo Educativo. In: LOPES, Eliane M. Teixeira et al. (Org.). 500 anos de Educação no Brasil. Belo Horizonte: Autêntica, 2010. p. 497-517.

VILELA, Carolina L. et al. A pesquisa em história das disciplinas e história do Currículo: investigando a recente produção brasileira. In: CONGRESSO BRASILEIRO DE HISTÓRIA DA EDUCAÇÃO, VI., 2011, Vitória. Anais... Vitória: UFES, 2011. CD-ROM. 
XAVIER, Libânia Nacif. O Manifesto dos Pioneiros da Educação Nova como divisor de águas na história da educação brasileira. FE/PROEDES - UFRJ. In: COLÓQUIO NACIONAL 70 ANOS DO MANIFESTO DOS PIONEIROS: um legado educacional em debate, 2002, Belo Horizonte e Pedro Leopoldo. Anais... Belo Horizonte e Pedro Leopoldo, ago. 2002. Disponível em: $<$ http://www.convenio1931.ence.ibge.gov.br/web/ ence/Libania_Manifesto.pdf>. Acesso em: 12 mar. 2014.

YOUNG, Michael. O currículo do futuro. Da nova sociologia da educação a uma nova teoria crítica do aprendizado. São Paulo: Editora Papirus, 2000.

Texto recebido em 17 de fevereiro de 2015. Texto aprovado em 13 de março de 2015. 